\title{
Psicologia Escolar e educação superior: possibilidades de atuação profissional
}

\author{
Alba Cristhiane Santana \\ Universidade Federal de Goiás - GO \\ Alciane Barbosa Macedo Pereira \\ Universidade Federal de Goiás - GO \\ Larissa Goulart Rodrigues \\ Instituto Federal de Goiás - GO
}

\section{Resumo}

Neste artigo apresentamos discussões sobre os desafios e possibilidades de atuação do psicólogo escolar na Educação Superior. Os contextos socioeconômicos e políticos contemporâneos têm gerado demandas ao ensino superior, provocando transformações nas instituições e no processo formativo e favorecendo o desenvolvimento de ações diversificadas. Essa situação possibilita a elaboração de projetos de pesquisa e de intervenção da Psicologia Escolar. Para ilustrar a discussão apresentamos um estudo realizado em uma instituição pública de ensino superior que teve como objetivo investigar as possibilidades de ações do psicólogo escolar com o foco em uma questão frequente nesse espaço educativo: as dificuldades encontradas por alunos ingressantes. O estudo demonstrou possibilidades de a Psicologia Escolar contribuir na gestão de políticas e práticas educativas que atendam às dificuldades apontadas por alunos e professores e também indicou desafios a serem superados, relacionados às concepções sobre a Psicologia Escolar e às características do processo formativo na Educação Superior.

Palavras-chave: Psicologia Escolar, ensino superior; atuação do psicólogo.

\section{Educational Psychology and Higher Education: possibilities of professional performance}

\begin{abstract}
In this paper we present discussions on the challenges and possible actions of the school psychologist in Higher Education. The contemporary socio-economic and political contexts have generated demands for Higher Education, causing changes in the institutions and in the training process, favoring the development of diversified actions. This situation enables the development of research projects and intervention of School Psychology. To illustrate the discussion we display a study of higher education in a public institution. Our aim is to investigate the possibilities of action for the school psychologist with the focus on a frequent issue in this educational space: the difficulties faced by new students. The study demonstrates the possibilities for School Psychology to contribute to the management of educational policies and practices that meet the difficulties pointed out by students and teachers. Besides, it also indicates challenges related to the conceptions of School Psychology and the characteristics of the educational process in Higher Education.
\end{abstract}

Keywords: school psychology, higher education, psychologist performance.

\section{Psicología Escolar y educación superior: posibilidades de actuación profesional}

\section{Resumen}

En este artículo presentamos estudios sobre la actuación del psicólogo escolar en la Educación Superior, esfera que se muestra favorable al desarrollo de proyectos diversificados. Se articuló la perspectiva histórico-cultural con una visión crítica de Psicología Escolar. Los estudios se realizaron en dos Instituciones de enseñanza superior en programas destinados a atender la inclusión educacional y la formación académica de discentes ingresos. Se destacan los análisis cualitativos de entrevistas realizadas con docentes y funcionarios técnico-administrativos de las instituciones, especialmente sus concepciones de las contribuciones del psicólogo escolar en ese contexto. Los análisis indican: a) atención centrada en el atendimiento al discente, al valorar sus dificultades cognitivo-emocionales y socioeconómicas; b) preocupación con la formación de los profesionales buscando el atendimiento de las dificultades de los alumnos; c) desconocimiento del trabajo del psicólogo escolar. Es necesario socializar, en el contexto de la Educación Superior, las posibilidades de actuación del psicólogo escolar a partir de proyectos que involucren a todos los participantes y los factores del proceso educativo.

Palabras Clave: Psicología Escolar; Educación Superior; actuación profesional. 


\section{Introdução}

A proposta deste artigo é discutir os desafios e as possibilidades da Psicologia Escolar no âmbito da Educação Superior, espaço visto como um contexto emergente de produção e atuação profissional. Na atualidade a Educação Superior tem vivenciado transformações e reformulações geradas por demandas dos contextos sociais, culturais e econômicos, bem como por orientações das políticas educacionais em vigência. Tal situação promove discussões acadêmicas, sociais e políticas que levam ao desenvolvimento de ações diferenciadas em prol de melhorias no seu processo educativo.

Ristoff (2006) aponta que o modelo de educação superior presente no século $X X$ já não se sustenta diante dos desafios da contemporaneidade. As reformas universitárias, orientadas pela legislação decorrente da Lei de Diretrizes e Bases da Educação Nacional (LDB) n 9394/1996, já são uma realidade e propiciam o planejamento e o desenvolvimento de variados projetos. Tal movimento visa atender às necessidades colocadas pela sociedade do conhecimento e da informação, por um mercado globalizado e pelos desafios de democratizar o acesso à Educação Superior, com investimentos em programas e modalidades diferenciadas, nos formatos presencial e à distância.

O contexto da Educação Superior precisa ser compreendido e estudado pelos psicólogos que pretendam desenvolver projetos de pesquisa e de atuação nesse espaço. Não é objetivo deste texto aprofundar-se em questões específicas daquele nível de ensino, mas é necessário pontuar algumas características que constituem esse contexto e representam os avanços e as contradições presentes na atualidade.

As políticas educacionais na área da Educação Superior têm-se apoiado no discurso da democratização do acesso e na qualidade da formação profissional. Segundo Dias Sobrinho (2010b), tais temas são recorrentes em todo o mundo. O autor destaca que o cenário da Educação Superior no País exige reflexões sobre os conceitos de democratização e de qualidade, com o objetivo de evidenciar os significados e as concepções que permeiam as propostas de reforma. Os investimentos na qualidade devem abranger as dimensões científica, social e pública do ensino, levando em conta não somente as especificidades desse processo educativo, mas também a importância desse nível de ensino no processo de construção da sociedade (Dias Sobrinho, 2010b; Weber, 2010).

As ações relacionadas à democratização da Educação Superior não podem se limitar à ampliação do acesso e do número de vagas com vistas a atender a inclusão social de pessoas historicamente distanciadas desse contexto educativo (Lessa, 2004), mas precisam analisar também as condições de permanência sustentável das pessoas nesse espaço para que consigam realizar seus estudos de forma adequada, considerando tanto as condições econômicas quanto os fatores socioculturais envolvidos com a aprendizagem.
A proposta de democratização e de melhorias na qualidade da Educação Superior promoveu o desenvolvimento de variadas reformas amparadas pela LDB n 9394/1996. Foram criados novos tipos de instituições de Ensino Superior (IES), como universidades especializadas, institutos superiores de Educação e centros universitários, os quais, somados às novas modalidades de cursos e programas, têm contribuído com a diversificação institucional existente hoje no Brasil. A citada lei ainda promoveu o desenvolvimento do sistema de avaliação da qualidade do processo educativo no nível superior, sistema que, conforme salienta Weber (2010), busca incentivar a ampliação do compromisso social das IESs com a formação global dos estudantes.

Dias Sobrinho (2010a) discute que a avaliação constitui-se como uma importante ferramenta para organização e implementação de reformas educacionais, pois tem o poder de gerar transformações nos currículos, nas metodologias de ensino, nos conceitos e práticas de formação e de gestão. No Brasil foi desenvolvido, a partir de 2004, o Sistema Nacional de Avaliação da Educação Superior (SINAES), com o objetivo de propiciar uma análise global e integrada das diferentes dimensões que compõem as instituições de Ensino Superior (IESs). Desde então, o SINAES assumiu um papel norteador das políticas educacionais na Educação Superior brasileira, conforme afirma Brito (2008).

As concepções iniciais do SINAES apontavam para possibilidades de mudanças qualitativas na gestão, pesquisa, extensão e formação profissional; no entanto, diversos estudiosos (Brito, 2008; Dias Sobrinho, 2010a; Goergen, 2010; Polidori, 2009) mostram-se críticos aos rumos tomados pela avaliação da Educação Superior nos últimos anos. As demandas amplas e contraditórias do contexto brasileiro, assim como conflitos em relação ao seu paradigma, geram dificuldades operacionais no desenvolvimento do SINAES. Dias Sobrinho (2010a) considera que a avaliação está perdendo seu caráter educacional de diagnóstico e de melhoria em função da ênfase no controle da eficiência e produtividade das IESs, e assim não tem contribuido para o fortalecimento de políticas de democratização do ensino com mais justiça social. Por outro lado, a despeito das dificuldades de desenvolvimento do SINAES, as políticas de democratização têm ampliado as vagas nas IESs privadas e aumentado as possibilidades de acesso ao nível superior de ensino.

Esse cenário propiciou a emergência de um aluno "novo", conforme Brito, Silva, Castilho e Abreu (2008), oriundo de um segmento social que até recentemente não tinha acesso a esse nível de educação. Os autores analisam o perfil desse novo aluno a partir de critérios relativos à formação escolar e cultural, ao apoio socioeconômico da família, à disponibilidade de tempo para os estudos e às expectativas acerca da formação acadêmica e do diploma de curso superior. O atual momento da Educação Superior brasileira motiva a produção de conhecimento sobre o seu estudante com o objetivo de compreender os resultados da democratização do acesso e as características de seu processo formativo nesse cenário de reformas, fator gerador de desafios e pro- 
blemas que devem ser enfrentados vigorosamente, segundo Dias Sobrinho (2010a).

O perfil do estudante de nível superior na atualidade, assim como as reformas nas estruturas das IESs e nos programas e currículos dos cursos, engendra novas configurações na Educação Superior do País. Tais transformações carregam contradições e imperfeições, a considerar a complexidade da educação, que é entendida como um fenômeno social de construção histórica a partir de múltiplos determinantes, e segundo alguns autores, dificilmente as políticas públicas conseguirão contemplar adequadamente todos os determinantes envolvidos com o fenômeno educativo (Dias Sobrinho, 2010a; Souza, 2010).

Entendemos que esse cenário é propício para o desenvolvimento de novos projetos, pois reflete a busca por possibilidades alternativas de educação com vistas a alcançar melhorias na formação acadêmica e profissional. A Psicologia Escolar pode participar desse cenário com projetos que contribuam para a reformulação da Educação Superior por meio de estudos, pesquisas e intervenções que focalizem os processos de ensino-aprendizagem e de desenvolvimento constituídos nesse espaço educativo.

Neste sentido, defendemos que a Educação Superior é um espaço fértil para a atuação do psicólogo escolar, com possibilidades e desafios que devem ser compreendidos e enfrentados por meio do conhecimento e desvelamento da realidade, bem como da construção conjunta de alternativas que visem à potencialização do processo educativo. Para discutir essa ideia se faz necessário contextualizar a Psicologia Escolar na Educação Superior a partir da exposição de alguns dos estudos desenvolvidos nessa área. Posteriormente, com o propósito de ilustrar e ampliar a discussão, é apresentado um estudo realizado em uma instituição pública de Ensino Superior que objetivou construir as possibilidades de atuação do psicólogo escolar nesse contexto a partir do levantamento das demandas realizado por meio do diagnóstico institucional.

\section{Psicologia Escolar e Educação Superior}

A Psicologia Escolar que compreendemos é uma área de conhecimento e de atuação profissional que tem como objeto o encontro entre o sujeito humano e a educação, com ênfase nas relações estabelecidas entre os processos psicológicos e os processos educacionais. Partimos dos autores Meira (2003), Mitjáns Martinéz (2010) e Souza (2007), os quais entendem a Psicologia Escolar como uma área que envolve o exercício profissional do psicólogo em diferentes contextos educativos, com base em um compromisso político, teórico e prático com as questões da Educação e com as necessidades sociais humanas. O psicólogo escolar deve ser envolver com uma multiplicidade de ações, considerando os determinantes sociais e os aspectos subjetivos que constituem os contextos educativos e o processo ensino-aprendizagem.
Os contextos escolares, especialmente a Educação Básica, têm se consolidado historicamente como o principal espaço de atuação do psicólogo escolar, com práticas que envolvem, segundo Marinho-Araújo (2009), dificuldades de aprendizagem, fracasso escolar, relação professor-aluno e família-escola, inclusão escolar, criatividade, superdotação, hiperatividade, entre outros. Nos últimos anos percebe-se uma ampliação dos espaços de atuação. Souza (2007) relata que a partir da década de 1990 uma série de pesquisas e propostas de atuação profissional em Psicologia Escolar vem buscando novos rumos, fundamentadas no conhecimento da realidade escolar, na articulação da dimensão educacional com as dimensões política, social, pessoal e institucional. Neste sentido têm surgido trabalhos em contextos educativos variados, como: abrigos, creches, organizações não governamentais, órgãos públicos de Educação e outros. Na última década, estudiosos da Psicologia Escolar têm desenvolvido ações no âmbito da Educação Superior, representando um movimento tímido, mas constante, que pode ser observado, por exemplo, nas publicações da Revista da Associação Brasileira de Psicologia Escolar e Educacional. Em uma rápida análise é possível identificar, a partir de 2006, pelo menos um trabalho em cada número da revista relacionado à pesquisa e/ou intervenção de Psicologia Escolar na Educação Superior.

A produção acadêmica nessa área tem apresentado pesquisas e intervenções com temas variados relativos a questões como: criatividade (Alencar \& Fleith, 2010); ações afirmativas (Sampaio, 2009); perfil dos discentes (Brito e cols, 2008; Oliveira \& Melo-Silva, 2010); relações interpessoais (Bariani \& Paviani, 2008); adaptação, integração e rendimento acadêmico (Carmo \& Polydoro, 2010; Rosário, Nunes, Magalhães, Rodrigues, \& Ferreira, 2010; Teixeira, Dias, Wottrich, \& Oliveira, 2008); estratégias de aprendizagem e métodos de estudo (Valle e cols., 2007); orientações motivacionais (Rosecler \& Guimarães, 2010; Santos, Mognon, Lima, \& Cunha, 2011), interesses profissionais, vivências acadêmicas e mercado de trabalho (Noronha, Martins, Gurgel, \& Ambiel, 2009); leitura, escrita e compreensão textual (Cabral \& Tavares, 2005; Cantalice \& Oliveira, 2009); Saúde de professores universitários (Rocha \& Sarriera, 2006), entre outros.

Não obstante, concordamos com Marinho-Araújo e Bisinoto (2011) e Sampaio (2010) em que esse é um espaço ainda pouco explorado e que demanda investimentos dos profissionais da área, principalmente se considerarmos o movimento de expansão e de reformas vivenciado na Educação Superior, o qual cria espaço para projetos variados.

Marinho-Araújo (2009) destaca as possibilidades de atuação da Psicologia Escolar na Educação Superior envolvendo os processos de reforma universitária, com a implantação das Diretrizes Curriculares Nacionais e da avaliação educacional, bem como os processos de formação continuada de docentes e técnicos, e de gestão institucional.

Observamos na literatura sobre o assunto que prevalecem estudos relativos ao estudante universitário e ao seu processo educativo. Quanto à atuação profissional, como 
aponta Sampaio (2010), o trabalho do psicólogo escolar se caracteriza por atendimento psicológico individual ou em grupo, avaliação psicológica ou de desempenho acadêmico e intervenções no processo ensino-aprendizagem. Tal situação lembra as intervenções tradicionais da Psicologia Escolar direcionadas à orientação e a atendimentos individuais, com pouco enfoque nos diferentes fatores que compõem o processo educacional. Entendemos que um dos desafios para a Psicologia Escolar é avançar em busca de uma prática crítica também na Educação Superior, que esteja atenta à realidade social imediata e tenha um caráter reflexivo quanto à construção de caminhos alternativos para a área.

O psicólogo escolar, por seus conhecimentos acerca dos processos subjetivos dos sujeitos e das instituições, pode contribuir, em alguma medida, para a implantação de políticas educacionais e transformações no processo educativo, conforme salienta Mitjáns Martínez (2007). Essa autora destaca que o papel desse profissional pode se expressar de diferentes formas, contribuindo com a adequação das políticas às condições da instituição, com a identificação e superação de obstáculos ao processo de mudanças e com o esclarecimento e o envolvimento dos diversos atores em busca de melhorias no processo educativo. Tais ações atendem às demandas que se colocam na atualidade da Educação Superior.

Souza (2010) afirma que "uma das contribuições importantes da Psicologia Escolar, no momento histórico em que se encontra, reside em explicitar os sentidos e os significados das políticas públicas para aqueles que possuem o estatuto institucional de planejá-las, no âmbito do sistema educacional, e de implantá-las na vida diária escolar" (p.141). Ao pensar na Educação Superior, essa autora ressalta a necessidade de conhecer a fundo as políticas em vigência e analisar como são apropriadas nesse espaço e como se concretizam nas práticas dos gestores, dos docentes e dos alunos.

O processo educativo é um fenômeno complexo e multideterminado que na Educação Superior se liga indissociavelmente à formação e ao desenvolvimento profissional e é engendrado por fatores de ordem econômica, política, social e cultural. Desse modo, a atuação do psicólogo escolar nesse cenário deve ir além do desempenho acadêmico dos sujeitos, focalizando também as especificidades da instituição de ensino, do processo educativo e da formação profissional. Marinho-Araújo (2009) entende que o trabalho do psicólogo escolar na Educação Superior pode contemplar três dimensões: 1-Gestão de políticas, programas e processos educativos nas IESs; 2- Propostas pedagógicas e funcionamento de cursos; e 3- Perfil do estudante.

De nossa parte, ao buscarmos práticas que favoreçam o desenvolvimento dos sujeitos, identificamos que a Educação Superior é um espaço privilegiado para o psicólogo escolar contribuir com o processo de desenvolvimento humano. Com base na Psicologia Histórico-Cultural e em estudos de Vygotsky (2003, 2010), percebemos o desenvolvimento humano a partir de sua contextualização histórica, social e cultural e na sua mediação pelos instrumentos materiais e simbólicos da cultura. O desenvolvimento é um processo que se configura nas relações dialógicas entre os sujeitos e os contextos histórico-culturais em que ocorrem processos de produção e negociação de significados que orientam os eventos e as ações.

Os significados têm uma natureza relacional e são produzidos nos processos sociais, em ações de negociação, confronto, consenso e comunicação (Bruner, 1997), e representam as interpretações que os sujeitos em interação fazem constantemente, a partir de conexões entre os símbolos de determinados contextos socioculturais, de situações relacionais e de suas próprias percepções. Tais interpretações conduzem a uma compreensão pessoal acerca do mundo e de si próprios.

Nessa perspectiva, o contexto educativo se torna espaço fundamental para gerar processos de desenvolvimento humano, por constituir-se de variadas relações dialógicas e intensos processos de significação. Especificamente a Educação Superior, abarca expressivos instrumentos materiais e simbólicos de nossa cultura, e particularmente carrega significados relacionados aos contextos acadêmicos e profissionais, os quais participam ativamente do desenvolvimento profissional dos alunos.

Nesse cenário, a Psicologia Escolar pode contribuir com pesquisas e ações que favoreçam uma formação acadêmica que efetivamente mobilize processos de desenvolvimento de docentes e discentes. Conforme aponta Marinho-Araújo (2009), ela pode também contribuir com a formação continuada de docentes e funcionários técnico-administrativos e com o acompanhamento e orientação dos discentes. O cotidiano acadêmico abrange diferentes eventos e situações que possibilitam as contribuições do psicólogo escolar. Como exemplo se pode citar a inserção e a permanência do aluno nesse espaço, situação que envolve as características do currículo, a ação do professor e as estratégias de acolhimento e orientação ao aluno. Assim, com vista a ampliar e ilustrar a discussão sobre os desafios e as possibilidades de atuação do psicólogo escolar na Educação Superior, apresentamos a seguir um estudo realizado em uma IES pública sobre as demandas do aluno da Educação Superior quanto à sua inserção e permanência e quanto às possibilidades de atuação do psicólogo escolar nesse contexto.

\section{A Psicologia Escolar no contexto acadêmico estudado: demandas e possibilidades}

As políticas públicas voltadas à Educação Superior têm investido no acesso a esse nível de ensino, contudo ainda não trouxeram contribuições significativas para a permanência do aluno nos cursos, conforme destacam alguns autores (Brito e cols., 2008; Dias Sobrinho, 2010a; Lessa, 2004). Estudos apontam que, ao ingressarem na Educação Superior, os alunos enfrentam diversas dificuldades relacionadas à dinâmica do processo educativo, as quais geram reprovação, evasão e desmotivação quanto à formação acadêmica (Carmo \& Polydoro, 2010; Igue, Bariani, \& Milanesi, 
2008; Oliveira \& Melo-Silva, 2010; Rosário e cols., 2010; Soares, Poubel, \& Mello, 2009; Teixeira e cols., 2008).

Os estudos de Carmo e Polydoro (2010) demonstram que as maiores dificuldades dos ingressantes no ensino superior estão relacionadas aos aspectos de bem-estar físico, bem-estar psicológico, envolvimento em atividades extracurriculares, relacionamento com professores, gestão de recursos econômicos e ansiedade na avaliação. Teixeira e cols. (2008) identificaram que o ingresso na universidade é sentido como um evento potencialmente impactante, gerando sentimentos de solidão, de insatisfação com o curso, com os professores, com os colegas e com o funcionamento da universidade.

Rosário e cols. (2010) observaram que a falta de competência dos alunos para o estudo gera dificuldades no processo de aprendizagem e na qualidade da formação acadêmica. Oliveira e Melo-Silva (2010) ressaltam que as condições financeiras do aluno e de sua família interferem na permanência na universidade e provocam a evasão diante das dificuldades enfrentadas. De modo geral, os estudos (Carmo \& Polydoro, 2010; Igue e cols., 2008; Teixeira e cols, 2008) indicam que a adaptação e permanência no Ensino Superior dependem de muitos fatores, por isso são necessários investimentos na forma de receber o aluno ingressante, com orientação no que diz respeito às dimensões pessoal, interpessoal, acadêmica, institucional e de carreira.

$\mathrm{Na}$ Educação Superior a pessoa começa a participar de um novo nível de ensino, com objetivos e procedimentos que diferem de forma significativa da Educação Básica. Este nível de ensino exige o desenvolvimento de habilidades e posturas que favoreçam a inserção no contexto. As características do processo ensino-aprendizagem, abrangendo metodologias de ensino e de avaliação, relação professor-aluno, material didático e outros fatores, requerem do aluno iniciativa e disciplina na organização de estratégias de estudo. Envolvem ainda características da IES como os serviços que são oferecidos, a forma de gestão e de acompanhamento aos alunos, por exemplo, que podem contribuir ou não com a inserção e permanência do aluno.

Diante dessa realidade, observa-se a necessidade de desenvolver projetos que atendam os atores envolvidos nesse processo - alunos, professores e gestores - com vistas a favorecer a inserção e a permanência no Ensino Superior. O psicólogo escolar tem diferentes possibilidades de contribuir com tais projetos, e uma importante ferramenta para o desenvolvimento de sua ação é o diagnóstico institucional, que é visto como um processo que objetiva compreender o movimento dos diversos elementos que compõem o contexto educativo.

Sobre a utilização do diagnóstico, Mitjáns Martinez (2006) discute que, em uma perspectiva crítica, essa estratégia não deve se limitar à avaliação psicológica dos alunos quanto a dificuldades de aprendizagem, distúrbios de comportamento ou sistemas de comunicação em sala de aula, mas deve ser objeto do diagnóstico também a instituição, com seus objetivos, concepções e ações, assim como as características de todos os sujeitos envolvidos com o contexto, como: a motivação de alunos, professores e funcionários; a satisfação de todos os atores com a instituição; a qualidade das relações interpessoais que permeiam o contexto, entre outros aspectos. Segundo a autora, uma concepção abrangente da função diagnóstica se relaciona com a crença na complexidade do processo educativo e a diversidade de seus condicionantes, e transcende as ações mais estreitas e parciais que têm caracterizado em diversos contextos o trabalho do psicólogo escolar.

Para Tanamachi e Meira (2003), mesmo que existam diferenças na articulação dos passos metodológicos que caracterizam os processos de intervenção em Psicologia Escolar, é possível sintetizar quatro momentos principais: 1avaliação da realidade escolar e/ou institucional; 2- discussão dos resultados preliminares com todos os segmentos da instituição educacional; elaboração do plano de intervenção; e 4- execução desse plano.

Dessa forma, o diagnóstico é uma possibilidade interessante para o trabalho do psicólogo escolar, pois a partir de uma questão específica, como a investigação sobre a inserção e permanência do aluno no Ensino Superior, é possível compreender os diferentes elementos que participam do contexto acadêmico e planejar projetos de intervenção.

Para ilustrar essas possibilidades, apresentamos um estudo desenvolvido em uma IES pública que teve como objetivo geral investigar formas de atuação do psicólogo escolar na Educação Superior. Para isso foi realizada uma breve avaliação institucional, fundamentada na concepção de diagnóstico apresentada anteriormente. A questão que se mostrou premente no contexto investigado foram as dificuldades de alunos ingressantes de um curso de licenciatura na área das ciências exatas. Na avaliação foram investigadas as percepções de alunos e professores acerca das dificuldades dos alunos ingressantes e ainda as percepções dos profissionais do curso a respeito da atuação do psicólogo escolar nesse contexto.

A pesquisa se baseou nos princípios da abordagem qualitativa e visou compreender os processos de significação produzidos no contexto acadêmico que orientam a ação dos sujeitos, conforme os estudos de Bruner (1997) e Vygotsky (2003).

O curso de licenciatura pesquisado tem, em média, 250 alunos matriculados em programas de graduação e mestrado, e de acordo com as informações do site consultado em setembro de 2013, tem como objetivo habilitar o diplomado a desempenhar funções de professor no Ensino Eédio como um profissional reflexivo, crítico e responsável pelo seu aperfeiçoamento contínuo. O curso é composto por quarenta professores com formação específica na área de exatas, e dois professores com formação na área de ensino.

Participaram trinta e sete alunos de duas turmas do primeiro período do referido curso; dois docentes do primeiro período e o coordenador desse curso. O critério de seleção dos participantes relacionou-se com a necessidade de incluir um gestor e docentes e discentes do primeiro período do curso. O coordenador, em um primeiro contato, apontou como problema significativo no curso as dificuldades dos 
alunos ingressantes, por isso entendemos que essa questão criou possibilidades para uma pesquisa em Psicologia Escolar.

Os procedimentos de pesquisa tiveram o papel de facilitar a expressão dos participantes, por meio de estratégias interativas que formaram um sistema integrado e possibilitaram a comunicação e a produção teórica (González Rey, 2005). Foi utilizado um questionário com questões fechadas acerca do perfil socioeconômico do aluno e questões abertas relacionadas às percepções dos alunos sobre as dificuldades de inserção no contexto acadêmico. O questionário foi aplicado em uma sala de aula na IES, em horário previamente estabelecido com os alunos. Foram realizadas entrevistas semiestruturadas com os docentes e o coordenador do curso, de forma individual, em horário estabelecido previamente e no contexto da IES. As entrevistas foram gravadas em áudio e posteriormente transcritas para análise.

A análise das informações construídas foi realizada por meio dos instrumentos estatística simples das questões fechadas do questionário e análise temática das questões abertas do questionário e das entrevistas, visando à identificação dos significados produzidos acerca do tema investigado. Foi realizada leitura detalhada e repetida de todo o material, com o objetivo de familiarização e identificação de dois aspectos: as percepções dos alunos e dos profissionais acerca das dificuldades dos alunos ingressantes; e as percepções dos profissionais sobre a atuação do psicólogo escolar no ensino superior.

Os procedimentos de análise possibilitaram a elaboração de eixos temáticos relativos aos objetivos do estudo, construídos por meio da organização de indicadores (Aguiar, 2006; González Rey, 2005), os quais representaram as unidades de sentido observadas em trechos das narrativas que foram selecionados por corresponderem aos dois aspectos citados anteriormente. Nesse exercício foram identificadas as seguintes marcações linguísticas: temas e conceitos recorrentes, padrões e contradições presentes, afirmação e negação, repetição ou reformulação, citação e alusão, discurso direto e indireto (Ludke \& André, 1986).

Os eixos foram: 1- Caracterização dos alunos e principais dificuldades apontadas por eles; 2- Concepções e percepções dos profissionais sobre a formação acadêmica dos discentes; 3- Percepções dos profissionais sobre as possíveis contribuições do psicólogo escolar na Educação Superior.

Dedicaremos nossa discussão ao terceiro eixo, por considerar os objetivos e os limites do presente artigo, e apresentaremos de forma breve os dois primeiros eixos.

No primeiro eixo - referente à caracterização dos alunos, foram feitas as seguintes caracterizações: os participantes eram jovens, com idades entre 17 e 19 anos (70\%); entre 20 e 23 anos (22\%) e acima de 23 anos (8\%); 95\% deles eram solteiros; $51 \%$ trabalhavam e $49 \%$ não trabaIhavam. Em relação aos fatores que dificultam a inserção no Ensino Superior, os alunos apontaram: dificuldade de organização pessoal para o estudo; ausência de conhecimento prévio na área de exatas; e problemas na relação professor-aluno, pelo temor dos alunos e pela intolerância dos professores com as dificuldades dos alunos. Tais fatores coincidem com os dados apresentados nas pesquisas sobre o ingresso na Educação Superior e com as análises acerca da qualidade do processo educativo nesse nível de ensino (Carmo \& Polydoro, 2010; Polidori, 2009; Rosário e cols., 2010; Sampaio, 2010; Teixeira e cols., 2008).

No segundo eixo, observamos que as percepções dos profissionais do curso sobre as dificuldades dos alunos ingressantes enfatizam: base deficitária dos alunos; problemas relativos às condições socioeconômicas dos alunos; distanciamento entre os docentes do curso; e falta de investimento em novas metodologias de ensino. Os professores indicam um contexto permeado por significados que atribuem os motivos das dificuldades ora aos alunos ora aos professores e suas metodologias, desconsiderando as relações estabelecidas entre gestores, professores e alunos, assim como fatores institucionais e as políticas educacionais, que também fazem parte do processo educativo (Mitjáns Martinéz, 2010).

Os dois primeiros eixos possibilitaram identificar as interpretações que alunos e professores fazem das dificuldades no primeiro período do curso, bem como revelaram concepções construídas nos contextos socioculturais em que os participantes estão inseridos. As percepções observadas evidenciam que a ampliação de vagas no Ensino Superior não implica na permanência do aluno na faculdade ou na qualidade da formação, como aponta Dias Sobrinho (2010b), pois são necessárias estratégias que auxiliem o processo ensino-aprendizagem.

Brito e cols. (2008) discutem que os "novos" alunos presentes no contexto da Educação Superior brasileira apresentam deficiência nos conhecimentos gerais de língua portuguesa e matemática, pouca habilidade de comunicação e de estudo, além de dificuldades financeiras, resultando em desistência no primeiro ano de curso. Tal situação exige novas formas de receber esses alunos e metodologias que atendam às suas necessidades; e quanto à percepção dos professores acerca do distanciamento entre eles e da falta de investimento em metodologias de ensino, acredita-se na necessidade de formação continuada. Segundo Masetto (2012), o docente do nível superior precisa aprender a lidar com as características do processo educativo na contemporaneidade a partir de cursos voltados para a docência.

O terceiro eixo se refere às percepções dos profissionais sobre as possíveis contribuições do psicólogo escolar na Educação Superior. De modo geral, foi possível perceber o desconhecimento sobre esse tipo de atuação. A concepção inicial dos professores entrevistados e do coordenador foi a de que o psicólogo é professor de "Psicologia da Educação", e não um profissional inserido e atuante na instituição.

Ao discutir as possibilidades de ação do psicólogo escolar os profissionais da IES atribuíram significados que evidenciavam o atendimento a alunos com dificuldades. $O$ trecho a seguir ilustra tais significados: "Seria muito chique. Contratar um psicólogo para atender todo mundo é bom" (professor A), "Eu acharia excelente um psicólogo no institu- 
to, porque o que eu recebia de pessoas lá... alunos chorando, alunos desesperados" (coordenador do curso); "Talvez se o psicólogo conseguisse levantar o astral do aluno (...) Junta os problemas pessoais dele, o trabalho, a vida dele" (professor B). As interpretações dos profissionais da IES sobre o psicólogo escolar traduzem concepções tradicionais que privilegiam as "dificuldades" como objeto da Psicologia Escolar, o que indica a necessidade de socializar as novas concepções da área.

Os profissionais demonstraram desconhecimento sobre o trabalho do psicólogo escolar, mas todos concordaram com a necessidade de alguém que acompanhe "psicologicamente" o aluno, pois o consideram "carente" financeira e emocionalmente. Em nenhum momento os profissionais conceberam uma contribuição do psicólogo escolar em relação aos diferentes fatores que compõem o processo educativo, como as propostas pedagógicas, a prática docente, o currículo e outros. Eles focalizam apenas o aluno que tem dificuldades pessoais, cognitivas, socioeconômicas: ele é que precisa de "atendimento".

Observamos que, ao realizar as entrevistas com os profissionais foi instigado o interesse em conhecer a Psicologia Escolar, e que o procedimento de pesquisa se configurou como um momento interessante de discussão sobre esse assunto. Um estudo deste tipo, diante do aparente desconhecimento com a atuação do psicólogo escolar na instituição estudada, pode servir como "porta de entrada" para esse profissional, conforme apontam Mitjáns Martinez (2006) e Marinho- Araújo (2009). A proposta de o psicólogo escolar realizar pesquisa e avaliação institucional representa uma possibilidade de intervir na produção de significados acerca do processo ensino-aprendizagem na Educação Superior, revendo o papel do currículo e das pessoas envolvidas.

As percepções dos profissionais da IES acerca da Psicologia Escolar são um desafio a ser enfrentado pelos psicólogos, pois demonstram falta de interlocução entre os psicólogos e os demais profissionais da Educação, professores e gestores, no que tange aos objetivos da intervenção psicológica em contextos educativos, especialmente na Educação Superior. Como diz Sampaio (2010, p.103), "Ainda que tenhamos avançado, resta-nos muito a fazer para que abandonemos de uma vez o restritivo e autoritário modelo medicalizado que impregna desde sempre nossa atuação".

Em relação às percepções de docentes e discentes sobre as dificuldades de inserção no Ensino Superior, foi evidenciada a importância de um trabalho coletivo e interdisciplinar na construção de estratégias que visem à superação de tal situação, uma vez que o aperfeiçoamento do processo educativo desenvolvido na Educação Superior exige ação conjunta de todos os envolvidos. As informações obtidas com o estudo indicam que a Psicologia Escolar pode oferecer importantes contribuições na gestão de políticas e práticas educativas que atendam às dificuldades apontadas por alunos e professores.

\section{Considerações finais}

O estudo apresentado, mesmo que de forma breve, aponta demandas e possibilidades de atuação do psicólogo escolar no contexto da Educação Superior, porquanto existem obstáculos para alcançar a proposta atual de investimento na qualidade do ensino e na democratização do acesso. O desenvolvimento do SINAES não tem gerado transformações na qualidade do processo educativo nem estratégias que favoreçam a permanência do aluno na Educação Superior (Lessa, 2004). O estabelecimento de rankings que revelam as "melhores" e as "piores" IESs, segundo Polidoro (2009), não tem ajudado o aluno ingressante a superar suas dificuldades no nível superior, questão que foi objeto de discussão neste estudo.

Concordamos com Mitjáns Martínez (2007) ao observarmos, a partir de nosso estudo, que é possível o psicólogo escolar contribuir para a implementação de políticas educacionais que respeitem as especificidades das IESs e favoreçam os processos de mudança, criando espaços de diálogo entre discentes, docentes e gestores e promovendo a identificação e a produção dos significados que constituem tal espaço. O psicólogo escolar também pode oferecer contribuições no sentido de esclarecer e envolver os diversos atores que compõem o contexto da Educação Superior, estimulando, por exemplo, a formação continuada dos docentes.

O processo de elaboração e desenvolvimento de projetos que atendam às exigências das políticas educacionais em vigência em relação à Educação Superior pode ser beneficiado com os conhecimentos oriundos da Psicologia acerca da constituição subjetiva dos sujeitos e das instituições sociais e educativas. Entendemos que o momento de reformas cria desafios e possibilidades para a Educação Superior e para a Psicologia Escolar na construção de um processo educacional que atenda às demandas e às contradições contemporâneas, e ainda contribua com a aprendizagem e o desenvolvimento humano.

Sobre as possíveis contribuições que o psicólogo escolar tem a oferecer à Educação Superior, vale destacar, conforme aponta Sampaio (2010), que o modelo de atuação ainda não existe e precisa ser construído a partir das características das IESs, dos projetos pedagógicos dos cursos e, principalmente, das especificidades e necessidades das pessoas envolvidas com o processo educativo, a saber, os alunos, os professores e os gestores.

\section{Referências}

Aguiar, W. M. J. (2006). A pesquisa junto a professores: fundamentos teóricos e metodológicos. Em W. M. J. Aguiar (Org.), Sentidos e significados do professor na perspectiva sócio-histórica: relatos de pesquisa (pp.11-22). São Paulo: Casa do Psicólogo.

Alencar, E. M. L. S., \& Fleith, D. S. (2010). Criatividade na educação superior: fatores inibidores. Avaliação, 15(2), 201-206. 
Bariani, I. C. D., \& Pavani, R. (2008). Sala de aula na universidade: espaço de relações interpessoais e participação acadêmica. Estudos de Psicologia, 25(1), 67-75.

Brito, M. R. F. (2008). O SINAES e o ENADE: da concepção à implantação. Avaliação, 13(3), 841-850.

Brito, L. P. L., Silva, E. O., Castilho, K. C., \& Abreu, T. M. (2008). Conhecimento e formação nas IES periféricas: perfil do aluno "novo" da educação superior. Avaliação, 13(3), 777-791.

Bruner, J. (1997). Atos de significação. Porto Alegre: Artes Médicas.

Cabral, A. P., \& Tavares, J. (2005). Leitura/compreensão, escrita e sucesso acadêmico: um estudo de diagnóstico em quatro universidades portuguesas. Psicologia Escolar e Educacional, 9(2), 203-213.

Cantalice, L. M., \& Oliveira, K. L. (2009). Estratégias de leitura e compreensão textual em estudantes universitários. Psicologia Escolar e Educacional, 13(2), 227-234.

Carmo, M. C., \& Polydoro, S. A. G. (2010). Integração ao ensino superior em um curso de pedagogia. Psicologia Escolar e Educacional, 14(2), 221-232.

Dias Sobrinho, J. (2010a). Avaliação e transformações da educação superior brasileira (1995-2009): do provão ao SINAES. Avaliação, 15(1), 195-224.

Dias Sobrinho, J. (2010b). Democratização, qualidade e crise da educação superior: faces da exclusão e limites da inclusão. Educação e Sociedade, 31(113), 1223-1245.

González Rey, F. L. (2005). Pesquisa Qualitativa e Subjetividade: os processos de construção da informação. São Paulo: Pioneira Thomson Learning.

Goergen, P. (2010). Educação superior na perspectiva do sistema e do plano nacional de educação. Educação e Sociedade, 31(112), 895-917.

Igue, E. A., Bariani, I. C. B., \& Milanesi, P. V. B. (2008). Vivência acadêmica e expectativas de universitários ingressantes e concluintes. Psico-USF, 13(2), 155-164.

Lessa, C. M. R. (2004). Democracia e universidade pública: o desafio da inclusão social no Brasil. Em M. C. L. Peixoto (Org.), Universidade e democracia: experiências e alternativas para a ampliação do acesso à universidade pública brasileira (pp.33-44). Belo Horizonte: Editora UFMG.

Ludke, M., André, M. (1986). Pesquisa em educação: abordagens qualitativas. São Paulo: EPU.

Marinho-Araújo, C. M. (2009). Psicologia escolar na educação superior: novos cenários de intervenção e pesquisa. Em C.
M. Marinho-Araújo (Org.), Psicologia escolar: novos cenários e contextos de pesquisa, prática e formação (pp. 155-202). Campinas, SP: Alínea.

Marinho-Araújo, C. M., \& Bisinoto, C. (2011). Psicologia Escolar na Educação Superior: Construindo possibilidades diferenciadas de atuação. Em R. S. L. Guzzo \& C. M. Marinho-Araújo (Orgs), Psicologia Escolar: Identificando e Superando Barreiras (pp. 193214). Campinas, SP: Alínea.

Masetto, M. T. (2012). Competência pedagógica do professor universitário. $2^{\mathrm{a}}$ edição. São Paulo: Summus.

Meira, M. E. M. (2003). Construindo uma concepção crítica de Psicologia Escolar: contribuições da Pedagogia Histórico-Crítica e da Psicologia Sócio-Histórica. Em M. E. M. Meira \& M. A. M. Antunes (Orgs.), Psicologia escolar: teorias críticas (pp.13-78). São Paulo: Casa do Psicólogo.

Mitjáns Martínez, A. (2006). O Psicólogo na construção da Proposta Pedagógica da Escola: áreas de atuação e desafios para a formação. Em S. F. C. Almeida (Org.), Psicologia escolar: ética e competência na formação e atuação profissional (pp. 105-124). Campinas, SP: Alínea.

Mitjáns Martinéz, A. (2007). O psicólogo escolar e os processos de implantação de políticas públicas: atuação e formação. Em H. R. Campos (Org.), Formação em psicologia escolar: realidades e pespectivas (pp. 109-134). Campinas, SP: Alínea.

Mitjáns Martinéz, A. (2010). O que pode fazer um psicólogo na escola? Em Aberto, 23(83), 39-56.

Noronha, A. P. P., Martins, D. F., Gurgel, M. G. A., \& Ambiel, R.A.M. (2009). Estudo correlacional entre interesses profissionais e vivências acadêmicas no ensino superior. Psicologia Escolar e Educacional, 13(1), 143-154.

Oliveira, M. D. A., \& Melo-Silva, L. L. (2010). Estudantes universitários: a influência das variáveis socioeconômicas e culturais na carreira. Psicologia Escolar e Educacional, 14(1), 23-34.

Polidori, M. M. (2009). Políticas de avaliação da educação superior brasileira: provão, SINAES, IDD, CPC, IGC e outros índices. Avaliação, 14(2), 439-452.

Ristoff, D. (2006). Introdução. Em D. Ristoff \& P. Sevegnani (Orgs.), Modelos Institucionais de Educação Superior. Brasília: Instituto Nacional de Estudos e Pesquisas Educacionais Anísio Teixeira.

Rocha, K. B., \& Sarriera, J. C. (2006). Saúde percebida em professores universitários: gênero, religião e condições de trabalho. Psicologia Escolar e Educacional, 10(2), 187-196.

Rosário, P., Nunes, T., Magalhães, C., Rodrigues, A., \& Ferreira, R. P. P. (2010). Processos de auto-regulação da aprendizagem em alunos com insucesso no $1^{\circ}$ ano de Universidade. Psicologia 
Escolar e Educacional, 14(2), 349-358.

Rosecler, A., \& Guimarães, S. E. F. (2010). Orientações motivacionais de alunos do curso de biblioteconomia. Psicologia Escolar e Educacional, 14(2), 211-220.

Sampaio, S. M. R. (2009). Explorando possibilidades: o trabalho do psicólogo na educação superior. Em C. M. Marinho-Araújo (Org.), Psicologia escolar: novos cenários e contextos de pesquisa, prática e formação (pp. 203-220). Campinas, SP: Alínea.

Sampaio, S. M. R. (2010). A Psicologia na educação superior: ausências e percalços. Em Aberto, 23(83), 95-105.

Santos, A. A. A., Mognon, J. F., Lima, T. H., \& Cunha, N. B. (2011). A relação entre vida acadêmica e a motivação para aprender em universitários. Psicologia Escolar e Educacional, 15(2), 283-290.

Soares, A. B., Poubel, L. N., \& Mello, T. V. S. (2009). Habilidades sociais e adaptação acadêmica: um estudo comparativo em instituições de ensino público e privado. Aletheia, 29, 27-42.

Souza, M. P. R. (2007). Reflexões a respeito da atuação do psicólogo no campo da psicologia escolar/educacional em uma perspectiva crítica. Em H. R. Campos (Org.), Formação em psicologia escolar: realidades e perspectivas (pp. 149-162). Campinas, SP: Editora Alínea.
Souza, M. P. R. (2010). Psicologia escolar e políticas públicas em educação: desafios contemporâneos. Em Aberto, 23(83), 129-149.

Tanamachi, E. de R., \& Meira, M. E. M. (2003). A Atuação do Psicólogo como Expressão do Pensamento Crítico em Psicologia e Educação. Em M. E. M. Meira \& M. A. M. Antunes (Orgs.), Psicologia escolar: Práticas críticas (pp.11-62). São Paulo: Casa do Psicólogo.

Teixeira, M. A. P., Dias, A. C. G., Wottrich, S. H., \& Oliveira, A. M. (2008). Adaptação à universidade em jovens calouros. Psicologia Escolar e Educacional, 12(1), 185-202.

Valle, A., Cabanach, R. G., Rodríguez, S., Núnez, J. C., GonzálezPienda, J. A., \& Rosário, P. (2007). Metas acadêmicas e estratégias de aprendizagem em alunos universitários. Psicologia Escolar e Educacional, 2(1), 31-40.

Vygotsky, L. S. (2003). A formação social da mente: o desenvolvimento dos processos psicológicos superiores (6a ed). São Paulo: Martins Fontes.

Vygotsky, L. S. (2010). A construção do pensamento e da linguagem (P. Bezerra, Trad., 2a Ed). São Paulo: Editora WMF Martins Fontes.

Weber, S. (2010). Avaliação e regulação da Educação Superior: conquistas e impasses. Educação e Sociedade, 31(113), 12471269.
Recebido em: 04/12/2012

Primeira Reformulação em: 20/12/2013

Segunda Reformulação em: 20/02/2014

Aprovado em: 23/04/2014

\section{Sobre as autoras}

Alba Cristhiane Santana (albapsico@gmail.com)

Universidade Federal de Goiás

Alciane Barbosa Macedo Pereira (barbosaalciane@gmail.com)

Doutoranda pela Universidade Federal de Goiás

Larissa Goulart Rodrigues (larissagr@gmail.com)

Instituto Federal de Goiás 